\title{
Assessment of non-genetic parameters of the racing performances of Arabian and Thoroughbred horses in Algeria
}

\author{
S. Tennah ${ }^{1,2}$, N. Kafidi ${ }^{2,3}$, N. Antoine-Moussiaux ${ }^{1}$, C. Michaux ${ }^{1}$, P. Leroy ${ }^{1}$ and F. Farnir ${ }^{1 *}$ \\ ${ }^{1}$ Division of Genetics and Biostatistics, Department of Animal Production, Faculty of Veterinary Medicine, \\ University of Liege, Sart Tilman, B43, 4000 Liege, Belgium. \\ ${ }^{2}$ Superior National Veterinary School of Algiers, BP 161 Hassen Badi El-Harrach, Algiers, Algeria. \\ ${ }^{3}$ Canadian Food Inspection Agency, Ottawa, Ontario K1A 0Y9 Canada.
}

Accepted 5 September, 2012

\begin{abstract}
From 1995 to 2007, flat racing data was collected for Thoroughbred and Arabian horses in Algeria. Nongenetic factors affecting racing performances have been identified and quantified using linear models. Performances are represented through the earnings and the rankings. Three traits were used: two earnings traits [the logarithm of annual virtual earnings (LAEV) and the logarithm of average annual virtual earnings per start (LAEV/S)], and one rank trait (the ranking transformed and normalised by application of the "performance rate" procedure, PERF). The results showed significant positive correlations $(p<0.001)$ between the three traits in the two breeds, showing that the measurements quantify similar - although different - aptitudes. The effects of sex, age, year of the performance and the interactions between age and sex and between age and year of the race turned out to be significant $(p<$ 0.05) for the three traits LAEV, LAEV/S and PERF for the Arabian horses. However, for Thoroughbreds, the sex effect was only significant for the PERF trait and an interaction between the age and year of the performance was the only significant interaction $(p<0.001)$ for the LAEV trait. The effects of these nongenetic factors will be used to correct the raw measures in a future genetic evaluation.
\end{abstract}

Key words: Earnings, non-genetic factors, flat racing, race-horses, rankings, Algeria.

\section{INTRODUCTION}

Flat racing in Algeria is a national tradition, which today needs to become more organized to stick to international standards and to face the laws of international competition. To that end, quantitative and qualitative assessment of the Algerian horses seems a necessary step. Qualitative assessment leads to the ideas of genetic evaluation of the potential of the animals, in order to be in a position allowing for reasoned choices to improve the overall quality of the population.

Assessing the genetic potential of each horse is

${ }^{*}$ Corresponding author. E-mail: f.farnir@ulg.ac.be. Tel: +32 4 36641 28. Fax: +32 4 - 3664122. therefore an important precondition. It is important to note here that the assessment of the genetic value of breeding animals has been applied to racehorses for many years and in many countries (Chico, 1994; Langlois, 1996; Belhajyahia et al., 2003; Langlois and Blouin, 2004; Sobczynska and Lukaszewicz, 2004; Ekiz and Kocak, 2005; Svobodova et al., 2005; Bokor et al., 2007; Bakhtiari and Kashan, 2009; Orhan and Kaygisiz, 2010). In Algeria, no selection program has been put in place and no assessment of the genetic additive value of breeding animals based on the performance of horses has been carried out till now despite the availability of reliable performance data.

The selection of animals and the assessment of their breeding values are based on one or several measurable 
traits expressed during races. A great variety of performance measures have been studied for flat-racing: this includes race times (Ekiz and Kocak, 2005; Ekiz et al., 2005; Bakhtiari and Kashan, 2009; Orhan and Kaygisiz, 2010), weight handicap (Langlois, 1980; Tolley et al., 1985), the performance rate (Watanabe, 1974), the final ranking (Belhajyahia et al., 2003; Ekiz and Kocak, 2005; Svobodova et al., 2005; Bakhtiari and Kashan, 2009) and the annual earning as well as the average earning per start (Langlois and Blouin, 1998; Belhajyahia et al., 2003; Ekiz and Kocak, 2005; Svobodova et al., 2005). Estimates of the heritability of traits related to time have been generally low, varying from 0.01 to 0.11 (Chico, 1994; Orhan and Kaygisiz, 2010). Consequently, most recent studies have been centered around traits linked to earnings or rankings, for which heritability (after convenient mathematical transformations) is higher (varying from 0.10 to 0.34), (Belhajyahia et al., 2003; Svobodova et al., 2005; Bakhtiari and Kashan, 2009).

For that reason, various objective quantitative measures of earnings and of rankings will be described in this study. The raw measures are supposed to reflect not only the genetic potential of the horses but also the environmental conditions (non-genetic factors) in which these observations have been made. Numerous studies have shown that these non-genetic factors strongly influenced the earnings and ranking of horses in flatracing (Langlois and Blouin, 1998; Belhajyahia et al., 2003; Sobczynska and Lukaszewicz, 2004; Ekiz and Kocak, 2005; Svobodova et al., 2005; Bokor et al., 2007; Bakhtiari and Kashan, 2009). In order to be able to estimate the genetic potential (breeding value) of the individuals, it is therefore important to determine the part played by the environment in the performances in the Algerian conditions.

This article is devoted on one hand to the estimation of phenotypic correlations between the used traits, in order to deduce what is common between these different performance measures and what is specific to each measure, and on the other, to the estimation of the impact of non-genetic factors such as sex, age, year of performance and their interactions.

\section{MATERIALS AND METHODS}

\section{Performances database}

The used data comes from results published monthly by the Algerian horse racing society and contains the results of gallop races over a 13 years period spanning 1995 to 2007 . This data includes information relative to each horse involved in a race (name, sire, dam, age and gender), information on the race (date of the race, the final rankings, the earnings and other informations). An interesting feature of the dataset is that results of all the participants to the race are provided, although the earnings are only attributed to the five first horses. Encoding this dataset produced 36492 results for the Arabian horses (a result corresponds to the performance of a horse in a race) obtained with 913 horses in 3086 races. The data for the Thoroughbred horses added 17790 results, obtained with 1032 horses in 2055 races.

Results for two-years horses, for which specific purses systems are used to promote their use, were removed from this study in order to eliminate the biases introduced by these special policies. Information on the genealogy was obtained from the Arabian horse Algerian stud book, recognized by international authorities such as the WAHO (World Arabian Horse Organization), while genealogy for the Thoroughbred was not available.

\section{The used traits}

The collected dataset allowed us to obtain traits linked to the earnings and to the final rankings of the horses in the races. Note that these traits provide distinct information: a second place in a good race (that is, with large earnings) might be better than a first place in a less prestigious competition.

In our analyses, we have applied the virtual earnings method of Chico (1994) for the horses obtaining no earning (that is, ranked above the fifth place). The principle is to attribute fictitious earnings to these horses, equivalent to $50 \%$ of what the preceding horse obtained, as is the case for the real earnings of the top five horses. This approach has allowed us to gain considerable information concerning the horses that ran but that did not qualify to gain money.

Other synthetic variables have been calculated for each horse, such as the annual virtual earning (AEV: total sum won per year), the total number of starts during a year, the average annual virtual earning per start (AEV/S: total sum won per year/ the total number of starts in the year), as well as the annual ranking (average annual ranking).

\section{Statistical analysis}

\section{Logarithmic transformation of earnings}

Given the way the earnings are attributed, the distribution of earnings is not normal and logarithmic transformation will be needed to assume a normal behaviour for this trait (Langlois, 1975). A logarithmic transformation was applied to the annual virtual earnings (LAEV) and the average annual earnings (LAEV/S), to allow their use in classical statistical analyses.

\section{Transformation of the rankings}

The ranks, varying from 1 to $\mathrm{n}$, do not follow a normal distribution. To make it normal, this variable was transformed using the method of Langlois (1984), (Langlois, 2007) which is based on the performance rate and used, for example, by Belhajyahia et al. (2003), Svobodova et al. (2005) and Bakhtiari and Kashan (2009). The principle is to attribute to each horse i a score $S_{i j}$ for the race $j$. The used score is a normalized score called the Blom score (Leroy and Farnir, 2002), integrating the fact that, given horses of the same level, it is generally more difficult to obtain a good ranking in a race where the number of participants is higher than in one where this number is lower. It is calculated through the formula:

$$
S_{i j}=\Phi^{-1}\left(\frac{r_{i j}-3 / 8}{n_{j}+1 / 4}\right)
$$

Where, $r_{i j}$ is the rank of the horse $i$ in the race $j, n_{j}$ is the number of 
participants in the race j, $\Phi^{-1}$ is the inverse standard normal cumulative distribution function, transforming probabilities into standard normal variable values.

Once the rank has been transformed into normalized performance, the level of the race must be taken into account, which is a simple function of the level of the competitors in that race. Therefore, two identical scores obtained by a horse in two events of different levels would correspond to different performances of the animal. The performance $\mathrm{Pij}$ of the horse $\mathrm{i}$ in race $\mathrm{j}$ could be represented by the addition of its score and the level of the event:

$$
P_{i j}=S_{i j}+E_{j}
$$

The level $E_{j}$ of race $j$ is taken to correspond to the average of the values $C_{k}$ of the horses that took part in that race:

$$
E_{j}=\frac{\sum_{k=1}^{n_{j}} C_{k}}{n_{j}}
$$

Finally, the value $C_{k}$ of a horse is estimated as the average of its performances $P_{i j}$ in the $m_{k}$ races in which it has participated:

$$
C_{k}=\frac{\sum_{l=1}^{m_{k}} P_{k l}}{m_{k}}
$$

Initializing the values of the variables with a well-chosen value, we can, by successive iterations, obtain a stable estimator of the performances $P_{i j}$ and a stable estimator of the value of horses $C_{k}$, which shall be used as traits in the remainder of this work. This value $C_{k}$ could be calculated on the whole career of the horse so providing one unique estimator per horse. Alternatively, annual $C_{k}$ values could be computed for each horse by using in the calculation only the races of the tested year. This later approach was followed in this study, meaning that horses have several (annual) observations for the PERF trait.

\section{Statistical analyses of the transformed traits}

The performance traits which have been analyzed in this study are the logarithm of annual virtual earnings (LAEV), the logarithm of average annual virtual earnings per start (LAEV/S) and the ranking value (PERF). The statistical analyses were carried out using SAS software (Statistical Analysis System, version 9.1.3). Descriptive statistics were obtained for the various traits. To analyze the effect of non-genetic factors, a linear fixed effects model was adjusted to the data and analyzed with the General Linear Models (GLM) procedure. The correlations between the three performance traits (LAEV, LAEV/S, and PERF) were obtained using the CORR procedure of SAS software.

The mathematical model used for the Arabian and Thoroughbred horses

$Y_{i j k n}=\mu+S_{i}+A g_{j}+A n_{k}+S_{i}{ }^{*} A g_{j}+S_{i}{ }^{*} A n_{k}+A g_{j}{ }^{*} A n_{k}+e_{i j k n}$

Where, $Y_{i j k n}=L A E V$, or LAEV/S or PERF of the $n^{\text {th }}$ horse of sex $i$, of age class $\mathrm{j}$, in the race year $\mathrm{k} ; \mu=$ general average; $\mathrm{S}_{\mathrm{i}}=$ fixed effect of the sex $\mathrm{i}\left(2\right.$ classes $\mathrm{F}$ and $\mathrm{M}$ ); $\mathrm{Ag}_{\mathrm{j}}=$ fixed effect of the age $\mathrm{j}$ ( 6 classes: $3,4,5,6,7$ and $>=8$ years); $A n_{k}=$ fixed effect of the race year $k$ (13 years: from 1995 to 2007); $A_{i}{ }^{*} B_{j}=$ interaction between the levels $i$ of the effect $A$ and $j$ of the effect $B$; $e_{i j k n}=$ residual random effect.

Since all traits are measured over all the races of each year, the age used is the age of the animal at the start of the considered year. The two-way interactions between the 3 factors were studied, and only those which were significant have been kept in the final model. For the three traits, the data distribution in the different classes of fixed effects is given in Table 1 for both breeds. The portion of the variation due to the model is provided through the coefficient of determination $\left(\mathrm{R}^{2}\right)$.

\section{RESULTS}

\section{Transformation of earnings (LAEV and LAEV/S) and rankings}

Descriptive statistics of the results of the transformation of earnings (LAEV and LAEV/S) and rankings (PERF) are given in Table 2.

\section{Relation between the 3 studied traits}

The correlation between LAEV, LAEV/S and PERF are given in Table 3 . They are of the same order of magnitude for the Arabian and Thoroughbred horses, and are all significantly $(p<0.001)$ positive and high.

\section{Descriptive statistics of the racing results for the Arabian and Thoroughbreds horses}

The number of observations, the average, and the standard deviation of the values LAEV, LAEV/S and PERF are given in Table 2. It is to be noted that the earnings are expressed in (logarithms of) Algerian dinars (for example, the average of the annual virtual earnings logarithm (LAEV), 10.38, corresponds to 32209 Algerian dinars).

\section{Estimation of non-genetic effects}

\section{Part of the variation of the three traits explained by the effects of the environment}

The results of the analyses presented in Table 4 show significant effect $(p<0.001)$ of sex, age and year of race for LAEV, LAEV/S and PERF in the case of the Arabian horse. The same applies to the Thoroughbred horses with the exception of sex which has no significant effect on the two earnings traits $(p>0.05)$. An interaction between the age and year of the race is significant for the three traits in the case of the Arabian horse and for LAEV in the case of the Thoroughbred horse. An interaction 
Table 1. Distribution of the data for the two breeds into different classes of sex, ages and of years.

\begin{tabular}{lccccc}
\hline \multirow{2}{*}{ Fixed effect } & \multicolumn{2}{c}{ Arabian horse (N = 3611) } & \multicolumn{2}{c}{ Thoroughbred (N = 2381) } \\
\cline { 2 - 6 } Sex & Observation & Percentage & Observation & Percentage \\
\hline & Male & 1782 & $(49.35)$ & 878 & $(36.88)$ \\
& Female & 1829 & $(50.65)$ & 1503 & $(63.12)$ \\
& & & & & \\
Age (years) & 3 & 592 & $(16.39)$ & 593 & $(24.91)$ \\
& 4 & 587 & $(16.26)$ & 552 & $(23.18)$ \\
& 5 & 515 & $(14.26)$ & 437 & $(18.35)$ \\
& 6 & 445 & $(12.32)$ & 327 & $(13.73)$ \\
& 7 & 388 & $(10.74)$ & 210 & $(8.82)$ \\
& $>=8^{\dagger}$ & 1084 & $(30.02)$ & 262 & $(11.00)$ \\
& & & & & \\
& 1995 & 234 & $(6.48)$ & 224 & $(9.41)$ \\
& 1996 & 235 & $(6.51)$ & 192 & $(8.06)$ \\
& 1997 & 250 & $(6.92)$ & 191 & $(8.02)$ \\
& 1998 & 275 & $(7.62)$ & 167 & $(7.01)$ \\
& 1999 & 280 & $(7.75)$ & 184 & $(7.73)$ \\
& 2000 & 290 & $(8.03)$ & 204 & $(8.57)$ \\
& 2001 & 258 & $(7.14)$ & 155 & $(6.51)$ \\
& 2002 & 265 & $(7.34)$ & 138 & $(5.80)$ \\
& 2003 & 283 & $(7.84)$ & 192 & $(8.06)$ \\
& 2004 & 274 & $(7.59)$ & 181 & $(7.60)$ \\
& 2005 & 317 & $(8.78)$ & 182 & $(7.64)$ \\
& 2006 & 320 & $(8.86)$ & 174 & $(7.31)$ \\
& 2007 & 330 & $(9.14)$ & 197 & $(8.27)$ \\
\hline
\end{tabular}

t: age >=8 Contains ages which vary from 8 to 20 years for Arabian horse and from 8 to 14 years for Thoroughbred.

Table 2. Elementary statistics for the raw data (AEV, AEV/S), the log-transformed data (LAEV, LAEV/S) and the performance (PERF) in the Arabian and Thoroughbred horses.

\begin{tabular}{lccccccccccc}
\hline \multirow{2}{*}{ Parameter } & \multicolumn{4}{c}{ Arabian horse $(\mathbf{N}=\mathbf{3 6 1 1})$} & \multicolumn{4}{c}{ Thoroughbred (N = 2381) } \\
\cline { 2 - 12 } & AEV & LAEV & AEV/S & LAEV/S & PERF & AEV & LAEV & AEV/S & LAEV/S & PERF \\
\hline Mean & 115329.05 & 10.38 & 11718.72 & 8.36 & 0.06 & 96513.839 & 10.28 & 14027.98 & 8.73 & 0.15 \\
Median & 85000.00 & 11.35 & 7778.05 & 8.96 & 0.07 & 53831.25 & 10.89 & 8883.33 & 9.09 & 0.12 \\
St. Dev. & 136788.72 & 2.43 & 13747.87 & 1.96 & 0.75 & 121404.83 & 2.13 & 16189.50 & 1.62 & 0.65 \\
Skewness & 3.49 & -1.40 & 2.53 & -1.22 & 0.11 & 2.56 & -1.11 & 2.49 & -1.12 & 0.23 \\
Kurtosis & 26.55 & 1.30 & 10.11 & 1.00 & -0.40 & 11.97 & 0.87 & 9.46 & 1.28 & -0.54 \\
\hline
\end{tabular}

St. Dev., Standard deviation.

Table 3. Correlation coefficients ( $r$ ) between the traits for the Arabian horse (over diagonal) and the Thoroughbred (below diagonal).

\begin{tabular}{llll}
\hline Parameter & LAEV & LAEV/S & PERF \\
\hline LAEV & & $0.95^{\star \star *}$ & $0.74^{\star \star *}$ \\
LAEV/S & $0.93^{\star * *}$ & & $0.81^{\star * *}$ \\
PERF & $0.76^{\star * *}$ & $0.81^{\star \star *}$ & \\
\hline
\end{tabular}

***: Significant at $p<0.001$. between age and sex is significant only for the Arabian horse and for the PERF trait. All these significant effects represent only modest parts of the total variation, with a highest contribution of only $13 \%$ for the PERF trait in the Arabian horse.

\section{Effects of the sex, the age and the year of the race}

The least squares means relative to the effects of sex, 
Table 4. Effect of the fixed factors and their interactions on LAEV, LAEV/S and PERF to the Arabian and Thoroughbred.

\begin{tabular}{|c|c|c|c|c|c|c|c|c|c|c|c|c|}
\hline \multirow{3}{*}{ Fixed effects } & \multicolumn{6}{|c|}{ Arabian horse $(\mathrm{N}=3611)$} & \multicolumn{6}{|c|}{ Thoroughbred $(\mathrm{N}=2381)$} \\
\hline & \multicolumn{2}{|c|}{ LAEV } & \multicolumn{2}{|c|}{ LAEV/S } & \multicolumn{2}{|c|}{ PERF } & \multicolumn{2}{|c|}{ LAEV } & \multicolumn{2}{|c|}{ LAEV/S } & \multicolumn{2}{|c|}{ PERF } \\
\hline & P-value & $\mathbf{R}_{\dagger}{ }_{\dagger}$ & P-value & $\mathbf{R}_{\dagger}^{2}$ & P-value & $\mathbf{R}^{2}{ }_{\dagger}$ & P-value & $\mathbf{R}^{2}{ }_{\dagger}$ & P-value & $\mathbf{R}^{2}{ }_{\dagger}$ & P-value & $\mathbf{R}_{\dagger}^{2}$ \\
\hline Sex & $* \star \star *$ & 0.02 & $* \star * \star$ & 0.03 & $* \star \star *$ & 0.05 & ns & & ns & & * & 0.002 \\
\hline Age & $* * *$ & 0.02 & $* * *$ & 0.02 & $\star * *$ & 0.03 & $* * *$ & 0.04 & $* * *$ & 0.02 & $\star * *$ & 0.02 \\
\hline Year of the race & $* * *$ & 0.01 & $* \star *$ & 0.02 & 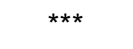 & 0.01 & $* \star \star$ & 0.02 & $\star * \star$ & 0.03 & $* \star \star$ & 0.02 \\
\hline $\mathrm{R}^{2}$ (model without interactions) & & 0.05 & & 0.07 & & 0.09 & & 0.06 & & 0.05 & & 0.04 \\
\hline Sex $x$ age & ns & & ns & & * & 0.003 & ns & & ns & & ns & \\
\hline Age $x$ year of the race & $* * *$ & 0.03 & $\star \star \star *$ & 0.03 & 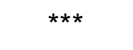 & 0.04 & * & 0.03 & ns & & ns & \\
\hline Sex $x$ year of the race & ns & & ns & & ns & & ns & & ns & & ns & \\
\hline $\mathrm{R}^{2}$ (model with interactions) & & 0.08 & & 0.10 & & 0.13 & & 0.09 & & 0.05 & & 0.04 \\
\hline
\end{tabular}

Ns, Not significant; at $p>0.05$; ${ }^{*}$, significant at $p<0.05$; ${ }^{* * *}$, significant at $p<0.001 .+$, only the values of $R^{2}$ for the significant effects are represented in the table.

age, and the year of the race in the two breeds are given in Table 5.

\section{Sex effect}

The superiority of the males over the females $(p<0.05)$ can be observed for LAEV, LAEV/S and PERF in the case of the Arabian horse: the females obtain, on average, fewer earnings than those obtained by the males and also have lower ranking values than those of the males. In the case of the Thoroughbred horses, the same tendency is observed although only significant for PERF $(p<0.05)$.

\section{Age effect}

Figures $1 \mathrm{a}$ and $1 \mathrm{~b}$ illustrate the effect of the age of the horses on the three traits. In the case of the Arabian horse, Figure 1a shows that the effect of age is similar for the three traits. The performances improve with age, reach a plateau between 5 and 7 years (mature age), and then decline. The difference between the horses of mature age (5 to 7 years) and the youngest (less than 4 years) or older horses (8 years and more) is significant ( $p$ $<0.05$ ) while the difference between the older and younger horses is not significant $(p>0.05)$. A more indepth analysis was carried out in order to compare the performances of younger and older horses: ages 8, 9, 10, and 11 and higher were compared with the age of 3 year old leading to the same conclusions. The performances continue to decline with age; however there are no significant differences between the ages of 3 and those of $8,9,10$, and 11 years and more for the three traits. It is to be mentioned that the seemingly sharp drop after 7 years is an artefact due to the pooling of the oldest horses, the reality being a more progressive decline with age after 8 years. Figure $1 b$ shows that similar profiles can be observed in the case of the Arabian horses except for an earlier deterioration of performances in the Thoroughbred horses (after 5 years). The difference between the horses of (4 to 5 years) and the youngest ( 3 years) is significant for PERF (Table 5). The difference is significant between the horses aged from (4 to 5 years) and those aged 7 and older, for all the variables. The difference between the old horses ( 8 years or more) and the youngest horses (3 years) is also significant $(p<0.05)$.

\section{Year of the race effect}

Figures (2a) and (2b), based on the least squares means shown in Table 5, illustrate the effect of the year of the race on the Arabian and Thoroughbred horses, respectively. In Arabian horses, the LAEV and LAEV/S, although fluctuating, have a significant linear growth $(p=$ 0.026 and $p<0.001$, respectively), with respective annual increases of 5.2 and $8.6 \%$ and respective $R^{2}$ of 0.37 and 0.84 (Figure 2a). For PERF, the linear regression is not significant $(p=0.335)$, and the residual variation is very high $\left(R^{2}=8 \%\right)$.

Results are similar for Thoroughbred horses, with significant $(p=0.015$ and $p=0.0001)$ linear regressions of the least square means of the earnings (LAEV and $\mathrm{LAEV} / \mathrm{S}$ ) on the race year, corresponding to respective annual increases of the earnings of 6.7 and $7 \%$ and to $\mathrm{R}^{2}$ of 0.43 and 0.75 (Figure $2 b$ ).

Linear regression for PERF is again not significant ( $p$ $=0.383$ ) and the coefficient of determination is very weak $\left(\mathrm{R}^{2}=7 \%\right)$.

\section{Effect of the interactions: Sex ${ }^{*}$ age and age ${ }^{*}$ year}

As shown in Figure 3 for Arabian horses, PERF 
Table 5. Least squares means (LSM) and standard error (SE) of the effects of the sex, the age, and the racing year on LAEV, LAEV/S and PERF to the Arabian and Thoroughbred horses.

\begin{tabular}{|c|c|c|c|c|c|c|c|c|c|c|c|c|c|c|c|c|c|c|c|}
\hline \multirow{3}{*}{ Fixed effect } & & \multicolumn{9}{|c|}{ Arabian horse } & \multicolumn{9}{|c|}{ Thoroughbred } \\
\hline & & \multicolumn{3}{|c|}{ LAEV } & \multicolumn{3}{|c|}{ LAEV/S } & \multicolumn{3}{|c|}{ PERF } & \multicolumn{3}{|c|}{ LAEV } & \multicolumn{3}{|c|}{ LAEV/S } & \multicolumn{3}{|c|}{ PERF } \\
\hline & & \multicolumn{2}{|c|}{ LSM } & \multirow{2}{*}{$\begin{array}{c}\text { SE } \\
0.06\end{array}$} & \multicolumn{2}{|c|}{ LSM } & \multirow{2}{*}{$\begin{array}{c}\text { SE } \\
0.05\end{array}$} & \multicolumn{2}{|c|}{ LSM } & \multirow{2}{*}{$\begin{array}{c}\text { SE } \\
0.02\end{array}$} & \multicolumn{2}{|c|}{ LSM } & \multirow{2}{*}{$\begin{array}{c}\text { SE } \\
0.08\end{array}$} & \multicolumn{2}{|c|}{ LSM } & \multirow{2}{*}{$\begin{array}{c}\text { SE } \\
0.06\end{array}$} & \multicolumn{2}{|c|}{ LSM } & \multirow{2}{*}{$\begin{array}{c}\text { SE } \\
0.02\end{array}$} \\
\hline Sex & Male & 10.83 & $\mathrm{a}$ & & 8.73 & $\mathrm{a}$ & & 0.28 & $\mathrm{a}$ & & 10.14 & $\mathrm{a}$ & & 8.75 & $\mathrm{a}$ & & 0.17 & $\mathrm{a}$ & \\
\hline & Female & 10.08 & $\mathrm{~b}$ & 0.06 & 8.07 & $\mathrm{~b}$ & 0.05 & 0.08 & $\mathrm{~b}$ & 0.02 & 10.03 & a & 0.06 & 8.63 & a & 0.04 & 0.11 & $\mathrm{~b}$ & 0.02 \\
\hline \multirow[t]{6}{*}{ Age (years) } & 3 & 10.22 & $\mathrm{ab}$ & 0.10 & 8.21 & a & 0.08 & 0.08 & a & 0.03 & 10.33 & ab & 0.09 & 8.74 & $a b c$ & 0.07 & 0.12 & a & 0.03 \\
\hline & 4 & 10.44 & $\mathrm{bc}$ & 0.10 & 8.33 & $a b$ & 0.08 & 0.09 & $\mathrm{~b}$ & 0.03 & 10.61 & a & 0.09 & 8.99 & a & 0.07 & 0.27 & $\mathrm{~b}$ & 0.03 \\
\hline & 5 & 10.68 & c & 0.11 & 8.56 & $\mathrm{~b}$ & 0.09 & 0.20 & $\mathrm{~b}$ & 0.03 & 10.55 & $\mathrm{ab}$ & 0.10 & 8.96 & a & 0.08 & 0.25 & $\mathrm{~b}$ & 0.03 \\
\hline & 6 & 10.66 & c & 0.12 & 8.59 & $\mathrm{~b}$ & 0.09 & 0.22 & $\mathrm{~b}$ & 0.04 & 10.15 & bc & 0.12 & 8.80 & $a b$ & 0.09 & 0.18 & $\mathrm{ab}$ & 0.04 \\
\hline & 7 & 10.74 & c & 0.12 & 8.66 & $\mathrm{~b}$ & 0.10 & 0.20 & $\mathrm{~b}$ & 0.04 & 9.69 & $c d$ & 0.15 & 8.45 & bcd & 0.11 & 0.07 & $\mathrm{ac}$ & 0.04 \\
\hline & $>=8$ & 10.00 & a & 0.08 & 8.06 & a & 0.06 & 0.04 & a & 0.02 & 9.19 & $d$ & 0.15 & 8.18 & $d$ & 0.10 & -0.04 & c & 0.04 \\
\hline \multirow[t]{13}{*}{ Racing Year } & 1995 & 10.16 & $\mathrm{a}$ & 0.16 & 7.95 & a & 0.13 & 0.04 & $\mathrm{ab}$ & 0.05 & 9.65 & $a b$ & 0.18 & 8.19 & $\mathrm{a}$ & 0.11 & 0.05 & a & 0.04 \\
\hline & 1996 & 10.01 & $\mathrm{a}$ & 0.16 & 7.94 & a & 0.13 & 0.06 & $a b$ & 0.05 & 9.46 & a & 0.23 & 8.19 & $\mathrm{a}$ & 0.12 & 0.05 & a & 0.05 \\
\hline & 1997 & 10.62 & $a b$ & 0.15 & 8.21 & a & 0.12 & 0.03 & $a b$ & 0.05 & 10.15 & abcd & 0.18 & 8.42 & $a b$ & 0.12 & 0.06 & a & 0.05 \\
\hline & 1998 & 10.03 & $a$ & 0.15 & 8.07 & $a$ & 0.12 & 0.01 & $\mathrm{~b}$ & 0.05 & 9.57 & $a b$ & 0.19 & 8.38 & $a b$ & 0.12 & 0.05 & $a$ & 0.05 \\
\hline & 1999 & 10.52 & $a b$ & 0.15 & 8.40 & $a b$ & 0.12 & 0.16 & $a b$ & 0.05 & 10.30 & abcd & 0.16 & 8.72 & $b c$ & 0.12 & 0.25 & $\mathrm{ab}$ & 0.05 \\
\hline & 2000 & 10.44 & $a b$ & 0.15 & 8.23 & a & 0.12 & 0.24 & $\mathrm{a}$ & 0.04 & 10.40 & bcd & 0.16 & 8.85 & bc & 0.11 & 0.28 & $\mathrm{~b}$ & 0.05 \\
\hline & 2001 & 10.69 & $a b$ & 0.17 & 8.52 & $a b$ & 0.13 & 0.11 & $a b$ & 0.05 & 10.01 & abcd & 0.18 & 8.94 & $\mathrm{bc}$ & 0.13 & 0.24 & $\mathrm{ab}$ & 0.05 \\
\hline & 2002 & 10.35 & $a b$ & 0.17 & 8.37 & $a b$ & 0.13 & 0.04 & $a b$ & 0.05 & 9.95 & abcd & 0.18 & 8.72 & $a b c$ & 0.14 & 0.14 & $a b$ & 0.06 \\
\hline & 2003 & 10.47 & $a b$ & 0.17 & 8.37 & $a b$ & 0.13 & 0.22 & $a b$ & 0.05 & 10.52 & $c d$ & 0.16 & 8.91 & $\mathrm{bc}$ & 0.12 & 0.26 & $a b$ & 0.05 \\
\hline & 2004 & 10.08 & $a$ & 0.15 & 8.42 & $a b$ & 0.12 & 0.02 & $\mathrm{~b}$ & 0.05 & 9.83 & $a b c$ & 0.18 & 8.71 & $a b c$ & 0.12 & 0.09 & $\mathrm{ab}$ & 0.05 \\
\hline & 2005 & 10.96 & $\mathrm{~b}$ & 0.15 & 8.81 & $\mathrm{bc}$ & 0.12 & 0.11 & $a b$ & 0.04 & 10.36 & abcd & 0.17 & 8.76 & $\mathrm{bc}$ & 0.12 & 0.13 & $a b$ & 0.05 \\
\hline & 2006 & 10.61 & $a b$ & 0.14 & 8.85 & $\mathrm{bc}$ & 0.11 & 0.09 & $a b$ & 0.04 & 10.20 & abcd & 0.16 & 8.97 & c & 0.12 & 0.07 & $\mathrm{ab}$ & 0.05 \\
\hline & 2007 & 10.99 & $\mathrm{~b}$ & 0.14 & 9.10 & c & 0.11 & 0.14 & $\mathrm{ab}$ & 0.04 & 10.72 & d & 0.15 & 9.17 & c & 0.11 & 0.17 & $\mathrm{ab}$ & 0.05 \\
\hline
\end{tabular}

$a, b, c, d$ : the difference between the groups with different letters is significant $(p<0.05)$.

difference between males and females remains approximately constant when the age of the animals increases, to drop after 7 years, with, at this age, the performances of males declining more rapidly than those of the females. Table 6 shows the interaction between the age of the horses and the year of the performance: performances of Arabian horses significantly $(p<0.05)$ increase with the year of performance only for the young animals ( 3 to 4 years for LAEV, 3 to 5 for
LAEV/S and 3 for PERF) while it remains stable deteriorates for older animals. Interestingly, the behaviour of Thoroughbred horses is very different, with only a significant increase of LAEV with the year of performance observed for older 

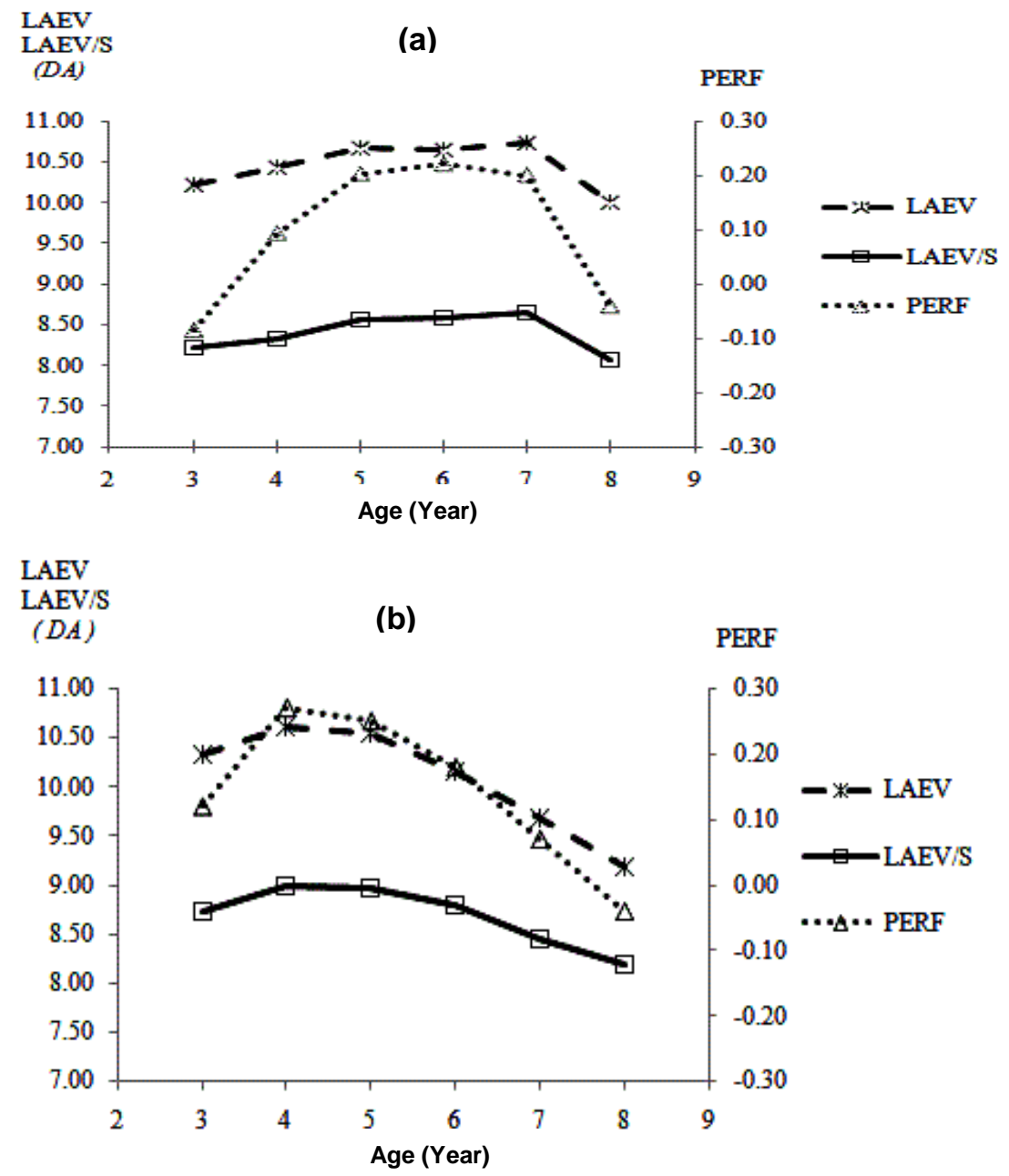

Figure 1. Effect of the age on three traits of performance to (a) the Arabian horse and (b) the Thoroughbred.

animals ( 7 to 8 years).

\section{DISCUSSION}

\section{Correlations between logarithm of annual virtual earnings (LAEV), logarithm of average annual virtual earnings per start (LAEV/S) and ranking value}

The high observed correlations (Table 3 ) confirm the results obtained by Belhajyahia et al. (2003) in the case of the Arabian horse, and those reported by Chico (1994) and Bugislaus et al. (2004) in the case of the Thoroughbred horses. Although the correlations between the traits are high, each trait reveals a different facet of the quality of a horse. The interest in using several traits is to take these various aspects into account. For example, we can criticize the use of earnings per start for the horses that have only one start: if, by chance, these horses obtain a good ranking, this performance trait can be overestimated as it is the result of one observation. It is more interesting to obtain the same result with several races. In this case, the total earnings trait will differentiate the two situations, with higher total earnings for the horse participating to several races. The total earnings can also be open to criticism: a horse that has several observations taken in low-level races can accumulate high earnings. Yet it is without doubt more beneficial to obtain these same earnings by being placed less often in more difficult events. All of these cases seem to have been relatively rare in view of the high correlations that we obtained. The three traits express similar potential and boil down to a single reality: the rankings of the horses in the races, eventually weighted by the quality of the race (PERF). These rankings therefore seem to be essential in the assessment of the performance of racehorses. The choice of phenotype for estimation of the breeding values of breeding horses will ultimately depend 

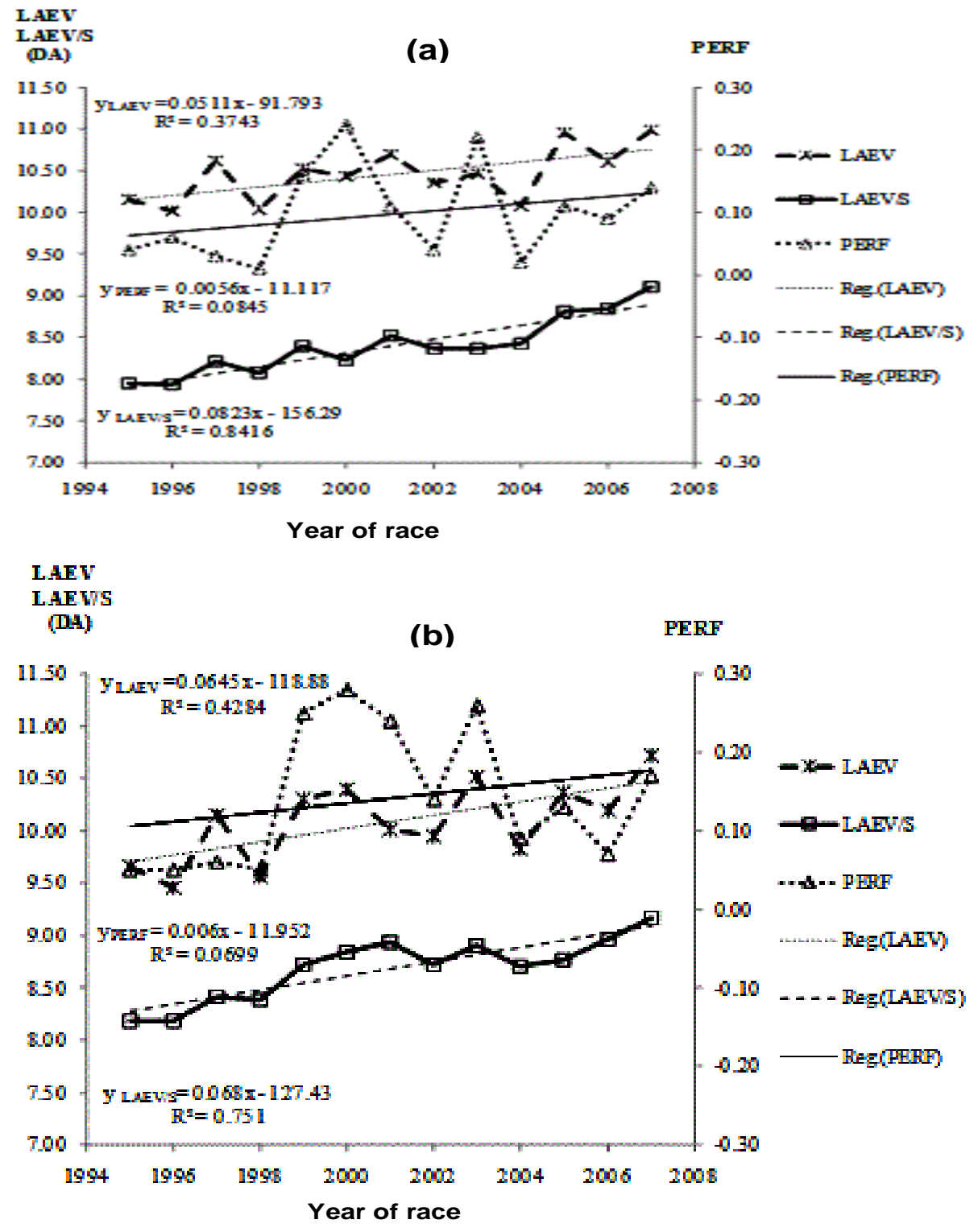

Figure 2. Effect of the year of race on three traits of performance to (a) the Arabian horse and (b) the Thoroughbred.

on selection objectives. The ranking value, when statistically normalized and transformed (PERF) seems a reasonable approach of the real rank of the horses, especially in our situation where the rankings are available for all the horses taking part to the races. It allows for a hierarchical ranking of all the horses, even if they have not met directly with each other. Another point of interest is that the transformed ranks presents a great advantage for international comparisons, because it is the same in all countries (Tavernier, 1990). The situation is different with earnings; indeed, the latter causes the level of the race to depend on the differences in prize money alone, without taking differences in quality between the involved horses into account. These prizes money depend on the national funding policy for racing and these policies might vary from one country to another. However, the earnings are also considered useful by the breeders to estimate the level of performance of the horses (Langlois and Blouin, 2004) and are a major objective of breeders as well as a criterion for comparison at the national level.

\section{Effect of the non-genetic parameters on the different traits}

Although significant, the part of the total variation of performance traits explained by the model (including the 


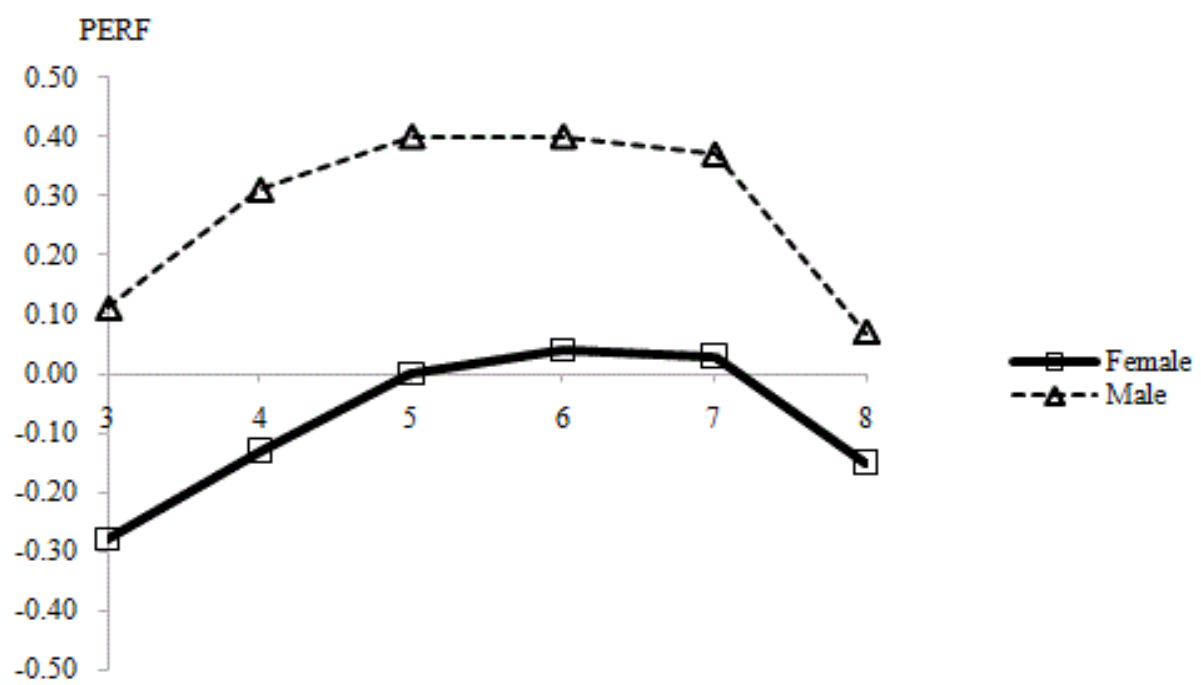

Age (Year)

Figure 3. Least squares means of the interaction between the age and the sex on the PERF to the Arabian horse.

Table 6. Linear regressions of the least squares means of the performance traits on the year of performance for the 2 breeds for the various age classes.

\begin{tabular}{|c|c|c|c|c|}
\hline \multirow{2}{*}{ Age } & \multicolumn{3}{|c|}{ Arabian horse } & \multirow{2}{*}{$\begin{array}{c}\text { Thoroughbred } \\
\text { LAEV }\end{array}$} \\
\hline & LAEV & LAEV/S & PERF & \\
\hline 3 & $\begin{array}{c}y=0.1265 x-242.86 \\
R^{2}=0.4900^{* *}\end{array}$ & $\begin{array}{c}y=0.1363 x-264.45 \\
R^{2}=0.6818^{\star * *}\end{array}$ & $\begin{array}{c}y=0.0294 x-58.856 \\
R^{2}=0.3556^{*}\end{array}$ & $\begin{array}{c}y=-0.0052 x+20.658 \\
R^{2}=0.0023^{n s}\end{array}$ \\
\hline 4 & $\begin{array}{c}y=0.1023 x-194.31 \\
R^{2}=0.4083^{*}\end{array}$ & $\begin{array}{c}y=0.1263 x-244.43 \\
R^{2}=0.628^{\star *}\end{array}$ & $\begin{array}{c}y=0.0168 x-33.532 \\
R^{2}=0.1568^{\text {ns }}\end{array}$ & $\begin{array}{c}y=0.0409 x-71.192 \\
R^{2}=0.0796^{\text {ns }}\end{array}$ \\
\hline 5 & $\begin{array}{c}y=0.0664 x-122.15 \\
R^{2}=0.2145^{\mathrm{ns}}\end{array}$ & $\begin{array}{c}y=0.1036 x-198.81 \\
R^{2}=0.4566^{*}\end{array}$ & $\begin{array}{c}y=0.0199 x-39.629 \\
R^{2}=0.2232^{\text {ns }}\end{array}$ & $\begin{array}{c}y=0.0459 x-81.263 \\
R^{2}=0.1844^{\text {ns }}\end{array}$ \\
\hline 6 & $\begin{array}{c}y=-0.0002 x+11.056 \\
R^{2}=1 E-06^{n s}\end{array}$ & $\begin{array}{c}y=0.0389 x-69.16 \\
R^{2}=0.1083^{n s}\end{array}$ & $\begin{array}{c}y=-0.0063 x+12.764 \\
R^{2}=0.021^{n s}\end{array}$ & $\begin{array}{c}y=0.0295 x-48.895 \\
R^{2}=0.0897\end{array}$ \\
\hline 7 & $\begin{array}{c}y=0.013 x-15.291 \\
R^{2}=0.0135^{n s}\end{array}$ & $\begin{array}{c}y=0.0585 x-108.33 \\
R^{2}=0.3896^{*}\end{array}$ & $\begin{array}{c}y=-0.0034 x+7.0196 \\
R^{2}=0.008^{n s}\end{array}$ & $\begin{array}{c}y=0.1445 x-279.36 \\
R^{2}=0.4007^{*}\end{array}$ \\
\hline$>=8$ & $\begin{array}{c}y=-0.0018 x+13.498 \\
R^{2}=0.0005^{n s}\end{array}$ & $\begin{array}{c}y=0.0295 x-50.867 \\
R^{2}=0.2497^{\mathrm{ns}}\end{array}$ & $\begin{array}{c}y=-0.0234 x+46.73 \\
R^{2}=0.3682^{*}\end{array}$ & $\begin{array}{c}y=0.1316 x-254.25 \\
R^{2}=0.3901^{*}\end{array}$ \\
\hline
\end{tabular}

not significant $(p>0.05),{ }^{*}: p<0.05,{ }^{* *}: p<0.01,{ }^{* * *}: p<0.001$

significant interactions) is not very high (Table 4). These weak $R^{2}$ values found in our study were also reported by Langlois (1975) and Langlois and Blouin (1998). All the significant fixed effects only explain a small part of the variation in the three performance traits. This means that other factors such as the jockey, the trainer and the owner influence the synthetic performances of the horses. In any event, in practice, the estimation of effects linked to the trainer and the owner is not always possible, because the majority of trainers and owners only own and train one horse, making their effect undistinguishable from the animal effect. In literature, Sobczynska and 
Lukaszewicz (2004), Svobodova et al. (2005) were not able to estimate the effect of the jockey; however, Oki et al. (1995) reported in their study that the talent of the jockey had a significant effect on the race time for different distances and different types of race tracks.

In our dataset, the effect of the jockey is difficult to estimate. To separate it from the horse effect, it would be necessary to have either a single jockey riding several horses, or reciprocally, the same horse mounted by several riders.

Preisinger et al. (1990) underlined the fact that the trainer is also an important non-genetic factors that should be taken into consideration. A risk in the evaluation of trainers is that horses are not allocated randomly to trainers: in reality, the best trainers are likely to train the best horses. Another potential problem is that a large number of horses per trainer is necessary in order to have a reasonable estimation, so introducing difficulties for a vast majority of trainers who only have observations on one (or very few) horse(s). An additional problem is the frequent stable change of horses, which could happen during the year, possibly several times (Langlois, 1982).

The owner factor is generally not taken into account in the statistical analyses, which might not be an issue according to certain authors (Langlois, 1975) who suppose that the majority of breeders of race horses have favourable breeding conditions at their disposal and are thus comparable.

\section{Sex effect}

For the three traits, in the case of the Arabian horse, the effect of sex was significant and was the most important of all the studied factors, especially for the PERF trait (Table 4). Our results agree with those found in the literature (Belhajyahia et al., 2003; Ekiz and Kocak, 2005). The differences in the race performances between the sexes are generally a reflection of the difference in the physiology of the males and females during the race (Jelinek, 1988). The effect of sex for the Thoroughbred horse was significant only for the PERF (Table 4), although with a modest contribution to the explanation of the observed variation. Some authors reported a significant effect of sex on the performance traits of earnings and rank for the Thoroughbred (Ekiz et al., 2005; Svobodova et al., 2005; Bokor et al., 2007) while some other did not find any evidence of a sex effect (Bakhtiari and Kashan, 2009). This absence of sex effect in Thoroughbred horses in our study, in contradiction with the results of other studies, could be due to errors regarding the publication of the sex of horses in raceresults by the racing society. Indeed, it was not possible for us to verify the information on these horses for the published results due to non-availability of the stud book for the Thoroughbred in Algeria, as we did for the Arabian horse. An indication that there could have been coding errors for the sex of the animals in the results is the significant unbalance between the numbers of males and females in this dataset (Table 1).

\section{Age effect}

In Arabian horses, the race performances improve between 3 and 7 years then, there is a tendency towards decline. Our interpretation is that the young horses (age < 4 years) have not had the chance yet to express their full potential and consequently, have worse performances than those of older horses. Belhajyahia et al. (2003), Ekiz and Kocak (2005) reported a significant age effect on rank and earnings.

The results that we found for the Thoroughbred horses match those in the literature (Langlois and Blouin, 1998; Ekiz et al., 2005). Indeed, performances improve with age, and then start to decline again. The age seems optimal around 5 years, and then the horses start to have worse results. The decline in performances with age could be partially explained by injury problems, lameness as well as osteo-articular problems caused by several years of racing. Indeed, several studies have found that the risk of injury increases with age (Williams et al., 2001). On the other hand, Pieszka et al. (2011) concluded that limb injuries are significantly more common in Thoroughbred race horses than in Arabians. Bailey et al. (1998) stated that horses of 4 or 5 years were 1.5 times more likely to suffer from an injury in relation to those who were aged from 2 to 3 years, the ratio going to 2 for horses of 6 years and more.

Another age effect should be mentioned: a common practice in horse breeding is to withdraw from the competitions horses with high performances at a young age. The rationale behind that behaviour is that these horses are expected to have a high potential for reproduction, with higher earnings to be obtained from reproductive activities than from the races themselves. Although this obviously introduces a bias in the estimation of the genetic values of these individuals, it also underlines the need for objective estimation procedures, which are one of the objectives of the present preliminary study.

\section{Year effect}

In the case of both the Arabian and Thoroughbreds horses, the earnings performances increased during the years 1995 to 2007. These annual variations of LAEV and LAEV/S could be explained by the variation in the purses with the years, in which a major part is played byinflation, as can be checked by adjusting the earnings 
for the observed inflation rates for those years (results not shown). The effect of the year on the earnings traits was also reported in various studies, with results similar to ours (Langlois and Blouin, 1998; Belhajyahia et al., 2003; Ekiz and Kocak, 2005; Svobodova et al., 2005; Bokor et al., 2007).

With regard to the significant effect of the year on the PERF trait in the two breeds, the "sawteeth" profile does not allow to identify any clear and stable trend with the year. These results could be due to other varying environmental conditions, such as training, breeding techniques, absence of training for trainers and jockeys, regular use of the horses among others. Another potential explanation of the profile could be the importation of racehorses by the Algerian government for years but not others.

An effect of the year on the rank was also recorded in various studies (Svobodova et al., 2005; Bokor et al., 2007), while other (Belhajyahia et al., 2003; Ekiz and Kocak, 2005) did not find any evidence of a year effect on this trait.

\section{Interactions effect}

The interaction between the sex and the age for PERF in Arabian horses is mainly due to a decline in the performances of the males aged over 7 years. This decline could possibly be explained by the differing productive lives trajectories between males and females: indeed, since females are withdrawn from racing for a certain period for reproduction, they presumably could perform longer and better than the males who continue racing and have more racing seasons than the females of the same age. Finally, it should be noted that a significant effect of interaction sex * age was demonstrated in other studies (Langlois and Blouin, 1998).

The interactions between the age of the animals and the year of the race for the Arabian horse for LAEV and LAEV/S, are essentially due to the politics of race purses that varies according to age over time and is combined with the effects of inflation (which explains the increase in estimates with year). Indeed, the purses of races vary with the year according to different age groups of horses. The interaction age * year for the PERF trait could be explained by politics of race in the recruitment of young horses and the withdrawal of the oldest. Indeed, the selection of young horses for the race is after their first year of racing at 2 years. The first years of racing are more and more reserved as a "test bench" for future racehorses. However, the promotion of young horses depends on the sports policy which varies with the years. The situation is similar and also dependent on political decisions for the retirement of older horses from 8 year of the racecourse. For the Thoroughbred horses, the interaction between the age and year observed for LAEV could be explained by the nature of importation of this breed into Algeria; It should be noted that the Thoroughbred horses are imported having already had a sporting career of 3 or 4 years of racing average in their country of origin (MADR, 2009). However, the ages of imported horses vary with the years. These imported horses benefitted from a better training than the Thoroughbred horses born and raised in Algeria. This would somehow indicate that the other environmental factors and particularly training have improved less with the years in Algeria than in exporting countries. A significant interaction between age and year has also been reported in other studies (Langlois and Blouin, 1998).

\section{Conclusions}

The results of correlations found between the three traits show that, overall, they take account of similar aptitudes which justifies the use of multiple traits to correctly define all the facets of the horse. This study on the subject of the performance racing of Arabian and Thoroughbred horses involved in flat racing has shown the significant effect of non-genetic factors such as sex, age, year of the race and the interactions between these factors, on the earnings traits (LAEV and LAEV/S) and ranking value (PERF). The demonstrated effects of the non-genetic factors indicate the need to adjust the earnings and ranks in the context of a program for genetic improvement of horses in Algeria.

\section{ACKNOWLEDGMENTS}

This study was supported by a mixed grant from the Algerian Ministry of Higher Education and Scientific Research and by the Belgian Technical Cooperation, (BTC) Brussels, Belgium.

\section{REFERENCES}

Bailey CJ, Reid SWJ, Hodgson DR, Bourke JM, Rose RJ (1998). Flat, hurdle and steeple racing: risk factors for musculoskeletal injury. Equine Vet. J. 30:498-503.

Bakhtiari J, Kashan NEJ (2009). Estimation of genetic parameters of racing performance in Iranian Thoroughbred horses. Livest. Sci. 120:151-157.

Belhajyahia T, Blouin C, Langlois B, Harzalla H (2003). Breeding evaluation of arab horses from their racing results in Tunisia by a BLUP with an animal model approach. Anim. Res. 52:481-488.

Bokor A, Nagy I, Sebestyen J, Szabari M (2007). Genetic trends in the Hungarian racehorse populations (preliminary results). Bulletin of University of Agricultural Sciences and Veterinary Medicine ClujNapoca. Anim. Sci. Biotechnol. 63/64:143-148.

Bugislaus AE, Roehe R, Uphaus H, Kalm E (2004). Development of genetic models for estimation of racing performances in German thoroughbreds. Archiv fur Tierzucht 47:505-516.

Chico MD (1994). Genetic-analysis of thoroughbred racing performance in Spain. Ann. Zootech. 43:393-397.

Ekiz B, Kocak O (2005). Phenotypic and genetic parameter estimates 
for racing traits of Arabian horses in Turkey. J. Anim. Breed. Genet. 122:349-356.

Ekiz B, Kocak O, Yilmaz A (2005). Phenotypic and genetic parameter estimates for racing traits of thoroughbred horses in Turkey. Archiv Fur Tierzucht-Archives Anim. Breed. 48:121-129.

Jelinek J (1988). Differences in the manifested racing performance of the English Thoroughbreds: Evaluation of horses of different sexes and years of birth by the parametric and non-parametric tests. Scientia Agriculturae Bohemoslovaca 20:131-138.

Langlois B (1975). Statistical and genetic analysis of the earnings of 3yr-old Thoroughbreds in French flat races. Ann. Génét. Sél. Anim. 7:387-408.

Langlois B (1980). Heritability of racing ability in Thoroughbreds - a review. Livest. Prod. Sci. 7:591-605.

Langlois B (1982). The heritability of performance in the French Trotter. A bibliographic review. Ann. Génét. Sél. Anim. 14:399-414.

Langlois B (1984). Horse of leisure and sport: capacities and selection. In: Jarrige R, Martin-Rosset W (ed.). The Horse, the reproduction, the selection, the supply, the exploitation. pp.423-435. INRA, Paris, France.

Langlois B (1996). A consideration of the genetic aspects of some current practices in Thoroughbred horse breeding. Ann. Zootech. 45:41-51.

Langlois B (2007). History of equestrian competitions and horse races. A symposium organized by the with the collaboration of the National Equitation School and the Horse Show., Ethnozootechnical Society, Paris p.198.

Langlois B, Blouin C (1998). Effect of a horse's month of birth on its future sport performance. II. Effect on annual earnings and annual earnings per start. Ann. Zootech. 47:67-74.

Langlois B, Blouin C (2004). Practical efficiency of breeding value estimations based on annual earnings of horses for jumping, trotting, and galloping races in France. Livest. Prod. Sci. 87:99-107.

Leroy P, Farnir F (2002). Calculation of the Index Jumping Individual Performance based on the performance of jumping in the Cycle Classic. P. 16. Seminars of 3rd doctoral, FMV ULG.
MADR (2009). Balance sheet of agricultural statistics 2008, SubDepartment of Statistics, Ministry of Agriculture and Rural Development Algeria p.25.

Oki H, Sasaki Y, Lin CY, Willham RL (1995). Influence of jockeys on racing time in Thoroughbred horses. J. Anim. Breed. Genet. 112:171175.

Orhan H, Kaygisiz A (2010). Genetic and Environmental Parameters Effecting Racing Performance of Turk-Arabian Horses Raised at Anatolian State Farm. Asian J. Anim. Vet. Adv. 5:12-119.

Pieszka M, Luszcynski L, Baranowska A (2011). Frequency of limb injuries between Thoroughbred and Arabian horses. Iranian J. Appl. Anim. Sci. 1(1):69-71.

Preisinger R, Wilkens J, Kalm E (1990). Breeding values and estimation of genetic trends in German Thoroughbred horses. Proceedings of the 4th World Congress on Genetics applied to Livestock Production 16:217-220.

Sobczynska M, Lukaszewicz M (2004). Genetic parameters of racing merit of thoroughbred horses in Poland. J. Anim. Breed. Genet. 121:302-306.

Svobodova S, Blouin C, Langlois B (2005). Estimation of genetic parameters of Thoroughbred racing performance in the Czech Republic. Anim. Res. 54:499-509.

Tavernier A (1990). Estimation of breeding value of jumping horses from their ranks Livest. Prod. Sci. 26:277-290.

Tolley EA, Notter DR, Marlowe TJ (1985). A review of the inheritance of racing performance in horses. Anim. Breed. Abstracts 53:163-185.

Watanabe $Y$ (1974). Performance rates of Thoroughbreds as a criterion of racing ability. Jpn. J. Zootech. Sci. 45:408-411.

Williams RB, Harkins LS, Hammond CJ, Wood JLN (2001). Racehorse injuries, clinical problems and fatalities recorded on British racecourses from flat racing and National Hunt racing during 1996, 1997 and 1998. Equine Vet. J. 33:478-486. 